\title{
$N$-Acetyl Cysteine in Combination with Vitamin C Enhances the Antioxidant Status of a Lung Carcinoma Cell Line in Vitro
}

\author{
Arambakkam Janardhanam VANISREE, Ramamurthy NALINI, ${ }^{\dagger}$ \\ and Cherran S. SHYAMALADEVI* \\ Department of Biochemistry, University of Madras, \\ Guindy Campus, Chennai 600025, India
}

(Received September 12, 1998)

\begin{abstract}
Summary The present study was carried out to evaluate the effect of $N$-acetyl cysteine and vitamin $\mathrm{C}$ on a lung carcinoma cell line. We studied the trypan blue exclusion pattern of a malignant lung cell line, NCI-H82, with and without supplementation of the drugs added alone or in combination. The levels of lipid peroxidation and glutathione were estimated in addition to the estimation of antioxidant enzymes. The results suggested the antiproliferative nature of the drugs, the effect being more when the drugs were added in combination. Both of the drugs could elevate the level of glutathione in lung cancer cells and the activities of antioxidant enzymes, thus minimizing the cancer-promoting, peroxidative damage to the cells.
\end{abstract}

Key Words: $N$-acetyl cysteine, vitamin C, lipid peroxidation, glutathione, antioxidant enzymes

Lung cancer remains an overwhelming oncologic problem because of its high incidence, low surgical curability, and the failure of conventional systematic treatments to cure it. More recently, $N$-acetyl cysteine (NAC) has gained widespread attention as a potential cancer chemopreventive agent against cancer [1]. It is generally accepted that lung cancer occurs in several steps. This multistep nature of the carcinogenic process raises the possibility of intervention at different stages [2]. Metabolism of carcinogens is affected and governed by the balance between opposite forces such as metabolic activation and detoxification (of carcinogens)

* To whom correspondence should be addressed. Present address: No. 62, II Main Road, Gandhi Nagar, Adyar, Chennai 600020, India

${ }^{\dagger}$ Present address: Virology Department, King Institute of Preventive Medicine, Guindy, Chennai 600032, India 
and consequent formation and scavenging of reactive metabolites (radicals) as well as damage and repair of DNA $[3,4]$. Metabolic conversion of carcinogens results in the formation of DNA adducts, which initiate carcinogenesis leading to gross tumors [5]. Hence the search has been under way for an agent that can act against reactive metabolites (radicals), thus acting against cancer.

It is reported that NAC was able to inhibit the formation of carcinogen-DNA adducts [6] which is regarded as one of the first steps of carcinogenesis. Vitamin $\mathrm{C}(\mathrm{VC})$, an antioxidant vitamin, on the other hand, is widely receiving attention as an anticancer vitamin. Initially, Cameron and Pauling [7] demonstrated that ascorbic acid has an antitumoral activity. Later on, several studies were carried out proving its anticancer effect [8-10].

Since free radical stress has been implicated in malignancy $[11,12]$, clinical trials of antioxidants are required to establish the efficacy of antioxidant therapy in the management of cancer. Therefore, the present study was designed based on the fact that NAC is a glutathione precursor and the hypothesis that combined factors, instead of a single agent, may be more beneficial against malignancy.

\section{MATERIALS AND METHODS}

Malignant lung cell line NCI-H82 was obtained from National Centre for Cell Science, Pune, India. The cells were maintained in RPMI-1640 containing $10 \%$ fetal calf serum, glutamine $(2 \mathrm{~mm})$ and the antibiotics penicillin (100 units/ $\mathrm{ml})$ and streptomycin $(100 \mu \mathrm{g} / \mathrm{ml})$. The cells were maintained in $7 \% \mathrm{CO}_{2} / 93 \%$ air.

The cells were seeded in tissue culture bottles at a cell density to ensure that cells were in their exponential phase at the time of experiments, with the lines refed with fresh medium $48 \mathrm{~h}$ prior to harvesting. The cells were divided into four groups: Group I, NCI-H82 (control); Group II, NCI-H82 supplemented with 15 mM NAC; Group III, NCI-H82 supplemented with $50 \mu \mathrm{g} / \mathrm{ml}$ of VC; Group IV, NCI-H82 supplemented with $10 \mathrm{mM} \mathrm{NAC}$ and $25 \mu \mathrm{g} / \mathrm{ml}$ of VC. The last group was included in order to evaluate the effect of the combination of NAC and VC in reduced concentrations compared with their single use in Groups II and III.

All of the groups were incubated for $48 \mathrm{~h}$ after the addition of the drugs to the last three groups. At the end of the incubation period, the cells were collected with a rubber policeman and were washed in ice-cold, phosphate-buffered saline. These cells were used for the following estimations after determining the trypan blue exclusion pattern [13].

Lipid peroxidation (LPO): LPO level was estimated by using thiobarbituric acid, and LPO was expressed as nanomoles of MDA [14].

Reduced glutathione: Reduced glutathione was estimated using dithionitrobenzoic acid, and the absorbance was read at $412 \mathrm{~nm}$ [15].

Superoxide dismutase (SOD): SOD activity was estimated by the method of Misra and Fridovich [16] using epinephrine oxidation. One unit of SOD activity was defined as that amount of protein required to give $50 \%$ inhibition of epineph- 
rine autooxidation.

Catalase (CAT): CAT activity was estimated by following $\mathrm{H}_{2} \mathrm{O}_{2}$ decomposition [17].

Glucose-6-phosphate dehydrogenase (G6PD) was estimated by the method of Bacquer and McClean [18], using glucose-6-phosphate and nicotinamide adenine dinucleotide phosphate (NADP).

Glutathione peroxidase (GSH-px): GSH-px was assayed by using dithionitrobenzoic acid, and the absorbance was read at $412 \mathrm{~nm}$ [19].

Glutathione- $S$-transferase (GST): GST was assayed by a conjugation with chlorodithionitrobenzene [20].

Glutathione reductase (GR): GR was assayed by following the method of Dubler et al. [21], with oxidized glutathione (GSSG) used as the substrate.

The experiments were done in triplicate and were repeated twice $(n=6)$. The statistical significance was assessed by Student's $t$ test, and $p$ values were expressed. The significance was accepted at $p<0.05$. All the data were expressed as the mean $\pm S D$.

\section{RESULTS}

From Fig. 1 it is evident that the viability of the cells was obviously greatest in Group I (cells without any supplementation of the drugs), as shown by the increased exclusion of the dye. The other consecutive groups, which had received NAC, VC, and both NAC and VC, showed a decrease in the exclusion of the dye.

It is evident from Table 1 that the level of lipid peroxidation was the most

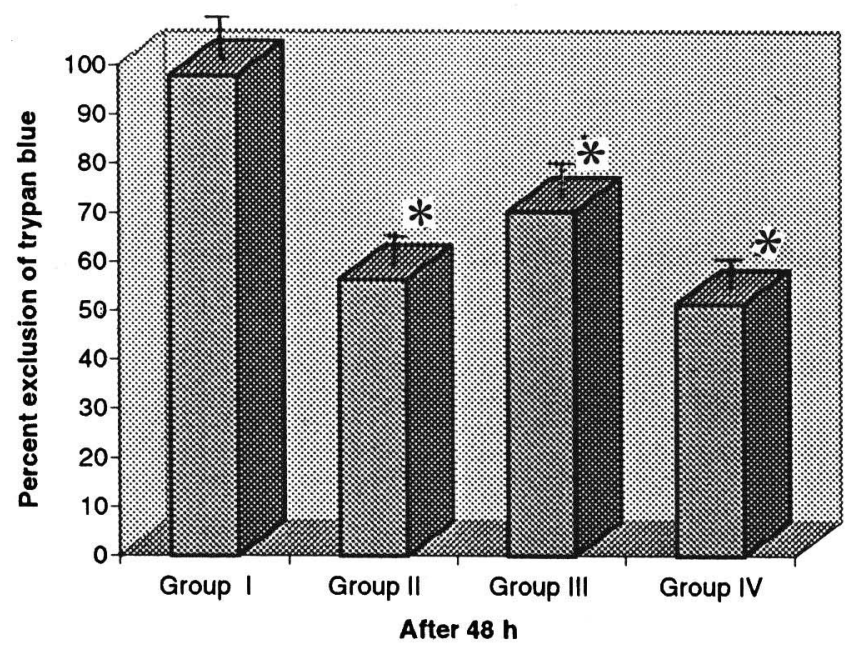

Fig. 1. Trypan blue exclusion pattern of the four groups. NCI-H82 Control (Group I), NCI-H82 + NAC (Group II), NCI-H82+VC (Group III), NCI-H82+NAC+VC (Group IV). $n=6,{ }^{*} p<0.001$, vs. Group I. Values are expressed as the mean \pm SD. 
pronounced in the cells without any supplementation. Upon supplementation with NAC and VC, the level of LPO was found to be considerably reduced in Group II $(p<0.001)$ and Group III $(p<0.05)$ when compared with that of Group I. The supplementation of combined drugs resulted in effective minimization of LPO $(p<0.001)$. GSH, which was found to be depleted in Group I was considerably elevated in Groups II $(p<0.001)$ and III $(p<0.05)$. Group IV showed profound elevation of GSH $(p<0.001)$, thus exhibiting the combative action towards the oxidative stress. The effect observed in Group IV suggests that the lower concentration of NAC could be used to achieve a similar beneficial effect if used in combination with VC with minimal side effects. This is an important point, because NAC has been reported to cause side effects such as nausea, vomiting, gastrointestinal disturbances, etc. [22].

Table 2 shows the activities of various antioxidant enzymes. The activities of SOD, CAT, and G6PD, which were found to be minimized in Group I, could be elevated by the drugs, both when added individually and in combination: NAC supplementation elevated the activity of SOD and of CAT in Group II $(p<0.01)$ when compared with those activities in Group I. VC also exhibited a considerable elevating effect on SOD and CAT ( $p<0.05$ and $p<0.02$, respectively). The activity of G6PD was found to be increased on the addition of NAC or VC $(p<0.01)$, which activity was found to be low in Group I without supplementation of the

Table 1. Levels of lipid peroxides and glutathione of the four groups.

\begin{tabular}{lcccc}
\hline Parameters & Group I & Group II & Group III & Group IV \\
\hline LPO (nmol of MDA $/ \mathrm{mg}$ protein) & $45.1 \pm 3.6$ & $28.3 \pm 2.0^{\mathrm{a}}$ & $40.1 \pm 2.2^{\mathrm{b}}$ & $24.3 \pm 1.8^{\mathrm{a}}$ \\
GSH (nmol/mg protein) & $35.0 \pm 2.8$ & $49.2 \pm 4.0^{\mathrm{a}}$ & $40.9 \pm 3.6^{\mathrm{b}}$ & $52.3 \pm 4.2^{\mathrm{a}}$ \\
\hline NCI-H82 Control (Group I), NCI-H82+NAC & (Group II), NCI-H82+VC $($ Group III), \\
NCI-H82+NAC+VC (Group IV). $n=6$, values are expressed as the mean \pm SD. ${ }^{\mathrm{a}} p<0.001$, \\
vs. Group I; ${ }^{\mathrm{b}} p<0.05$, vs. Group I.
\end{tabular}

Table 2. Activities of antioxidant and glutathione-dependent enzymes of the four groups.

\begin{tabular}{lrrrr}
\hline Parameters & Group I & Group II & Group III & Group IV \\
\hline SOD & $18.9 \pm 2.0$ & $23.6 \pm 1.9^{\mathrm{b}}$ & $22.6 \pm 2.5^{\mathrm{d}}$ & $30.6 \pm 3.0^{\mathrm{a}}$ \\
CAT & $10.1 \pm 1.0$ & $15.6 \pm 3.4^{\mathrm{b}}$ & $13.3 \pm 2.0^{\mathrm{c}}$ & $17.1 \pm 1.9^{\mathrm{a}}$ \\
G6PD & $3.1 \pm 0.4$ & $4.0 \pm 0.2^{\mathrm{b}}$ & $4.0 \pm 0.1^{\mathrm{b}}$ & $5.6 \pm 0.4^{\mathrm{a}}$ \\
GSH-px & $10.2 \pm 1.0$ & $34.2 \pm 2.8^{\mathrm{a}}$ & $27.2 \pm 3.1^{\mathrm{a}}$ & $57.6 \pm 5.0^{\mathrm{a}}$ \\
GST & $19.3 \pm 1.8$ & $25.2 \pm 2.2^{\mathrm{b}}$ & $22.5 \pm 2.0^{\mathrm{d}}$ & $26.4 \pm 2.6^{\mathrm{b}}$ \\
GR & $80.0 \pm 7.9$ & $110.3 \pm 10.7^{\mathrm{b}}$ & $99.8 \pm 8.7^{\mathrm{b}}$ & $123.6 \pm 11.7^{\mathrm{a}}$ \\
\hline
\end{tabular}

NCI-H82 Control (Group I), NCI-H82+NAC (Group II), NCI-H82+VC (Group III), $\mathrm{NCI}-\mathrm{H} 82+\mathrm{NAC}+\mathrm{VC}$ (Group IV). $n=6$, values are expressed as the mean $\pm \mathrm{SD}$. ${ }^{\mathrm{a}} p<0.001$, vs. Group I; ${ }^{\mathrm{b}} p<0.01$, vs. Group I; ${ }^{\mathrm{c}} p<0.02$, vs. Group I; ${ }^{\mathrm{d}} p<0.05$, vs. Group I. SOD, units/ $\mathrm{mg}$ protein; CAT, nmol of $\mathrm{H}_{2} \mathrm{O}_{2}$ consumed $/ \mathrm{min} / \mathrm{mg}$ protein; G6PD, untis/mg protein; GSH-px, nmol of GSH utilized/min/mg protein; GST, nmol CDNB conjugated/min/mg protein; GR, nmol NADPH utilized/min/mg protein. 
drugs. The supplementation with the combined drugs resulted in significant elevation in the activity of G6PD $(p<0.001)$ when the activity of Group IV was compared with that of Group I.

The activities of glutathione-dependent enzymes, namely, GSH-px, GST, and GR, were observed to be increased on supplementation with the drugs. The activity of GSH-px, showing a comparative increase $(p<0.001)$, was found to be associated with the individual supplementation with either NAC or VC. Their combination also effectively resulted in the increased activity of GSH-px. The activity of GST was elevated on NAC supplementation $(p<0.01)$ and on VC supplementation $(p<$ $0.05)$, as well as when both $(p<0.01)$ were added. The activity of GR was found to be elevated by individual supplementation with NAC or $\mathrm{VC}(p<0.01)$, and the combination of the drugs likewise caused a significant elevation in the activity of GR $(p<0.001)$.

\section{DISCUSSION}

Thiol groups (SH) are essential in the protection against the deleterious effects of reactive oxygen species and hence against cancer. Since these reactive oxygen species are said to be candidates for the development of malignancy [23], it seems, therefore, that the level of GSH, an antioxidant, would be important in view of cellular responses to cytotoxic drugs. The observed reduction in the level of GSH and activities of antioxidant enzymes in the control NCI-H82 cells compared with those of normal cells confirms the observation of Carmichael et al. [24], who demonstrated a reduction in the activity of SOD and of CAT in various human cancer cell lines. This depletion of GSH could be due to the oxidative burden in lung cancer cell line. It is also evident from the elevated LPO in Group I, since it is thought that the depletion of GSH is the result of enhanced LPO [25]. This depleted GSH could be responsible for the decreased activities of GSH-dependent enzymes. In the present study, the reduced activity of GR in NCI-H82 cells, which enzyme is responsible for the regeneration of reduced glutathione, would also be partially responsible for the depleted GSH in Group I.

Byproducts of LPO exert severe damage to DNA by causing base hydroxylation and strand breaks. This damage can lead to malignant transformation of cells [26]. Lung cancer is the result of exposure to carcinogens such as oxidants contained in cigarette smoke $[11,12]$. Elevated LPO was proven in the lung malignant cells in present study, as a consequence of GSH depletion.

The activities of SOD and CAT showed a reduction because of the excessive LPO, which exceeded the ability of these free radical scavenging enzymes to dismute the radicals. NAC supplementation, on the other hand, elevated the level of GSH, thus suppressing LPO experimentally. Since LPO could be suppressed by NAC, the oxidative burden to SOD and CAT could be reduced, resulting in comparative elevation of their activities after supplementation.

NAC, as a precursor of GSH, is also capable of stimulating enzymes in the Vol. 26, No. 1, 1999 
GSH cycle [27]. This is supported by our observation of the comparative increase in the activities of GST, GSH-px, and GST on supplementation with NAC. The protective effect of NAC on the cancer cell line might also be due to its ability to alter the redox balance of GSH [28], and NAC is said to be consumed more rapidly in the process of protection against cancer cell lines. It is also said that in vitro NAC is able to activate GR, thus enabling rapid GSH regeneration [27].

The increased activities of G6PD and GST confirmed other studies demonstrating increased activities of these enzymes after the administration of NAC [29, 30]. Dietary NAC is said to enhance the activity of GST [31]. NAC both when added individually and in combination led to the enhancement of GST activity. GST has been reported as a metabolic biomarker for predisposition to lung neoplasms, and low or normal activity of these enzymes is associated with increasing incidence of lung cancer [32]. Hence, by stimulating the activity of GST, NAC seems to be effective against lung cancer.

$\mathrm{VC}$ is a redox compound that acts as an antioxidant to prevent LPO by quenching free radicals [33]. VC, an effective antioxidant vitamin, acts in combination with GSH against destructive reactive oxygen species. GSH reacts with reactive oxygen compounds, and it functions in the reduction of hydrogen peroxides and organic peroxides in reactions catalyzed by GSH-px (selenium-containing and other). It is well known that ascorbate can also interact with peroxides and other reactive oxygen forms. Such reactions occur nonenzymatically, but the interaction between hydrogen peroxide and ascorbate is enzyme catalyzed in chloroplasts, cyanobacteria, and soybeans $[33,34]$, and an analogous reaction may occur in mammalian tissues. It is possible that $\mathrm{VC}$ reduces compounds that are not directly reduced by GSH. VC thus protects the GSH content of the cancer cell line, as was evident from the comparative increase in GSH in Groups II and IV over that in Group I. By dismuting free radicals, VC also reduces the oxidative burden against antioxidant enzymes, as was evident from the elevated activities of these enzymes on supplementation.

GSH is said to prevent both tumor promotion [35] and progression [36]. From our results, it is evident that NAC enhances the level of GSH and VC reduces the oxidative burden to GSH and thus protects it. By this activity and by increasing the activities of CAT and SOD, which have been reported to prevent oxidant-induced DNA damage [37], NAC and VC could prevent further damage to DNA of lung cancer cells, thus controlling the malignancy. Our observations suggest the enhancement of antioxidant status of NCI-H82 on supplementation with NAC and VC and the inhibitory action of the drugs on the growth of malignant lung cells.

\section{REFERENCES}

1. De Flora, S., Izzotti, A., and D'Angostini, F. (1992): Chemopreventive properties of $\mathrm{N}$-acetyl cysteine and other thiols, in Cancer Chemoprevention, ed. by Wattenberg, L., 
Lipkin, W., and Boone, C.W., CRC Press, Boca Raton, Florida, pp. 183-184.

2. Weinstein, I.B. (1991): Cancer prevention: Recent progress and future opportunities. Cancer Res., 51 (Suppl.), 503S-508S.

3. De Flora, S., and Ramel, C. (1988): Mechanism of inhibitors of mutagenesis and carcinogenesis: Classification and overview. Mutat. Res., 202, 285-306.

4. Micozzi, M.S., and Tangrea, J.A. (1989): General introduction: Rationale for the nutritional prevention of cancer, in Nutrition and Cancer Prevention: Investigating the Role of Micronutrients, ed. by Moon, T.E., and Micozi, M.S., Marcel Dekker, New York, pp. 3-12.

5. Miller, J.A., and Miller, E.C. (1983): The Metabolic Activation and Nucleic Acid Adducts of Naturally-Occurring Carcinogens: Recent Results with Ethyl Carbamate and the Spice Flavours Safrole and Estragole, Walter Hubert Lecture, Thieme-Verlag, Stuttgart.

6. Izzotti, A., Bagnasco, M., and D'Agostini, F. (1991): Chemoprevention of carcinogen-DNA adduct formation, in Chemoimmunoprevention of Cancer, ed. by Pastorino, U., and Hong, W.K., Thieme-Verlag, Stuttgart, pp. 15-19.

7. Cameron, E., and Pauling, L. (1973): Ascorbic acid and glycosaminoglycans-an orthomolecular approach to cancer and other diseases. Oncology, 27, 181-192.

8. Benedict, W.F., Wheatley, W.L., and Jones, P.A. (1980): Inhibition of chemically induced morphological transformation and reversion of the transformed phenotype by ascorbic acid in $\mathrm{C} 3 \mathrm{H} / 10 \mathrm{~T} 1 / 2$ cells. Cancer Res., 40, 2796-2801.

9. Mizumoto, M., Nakae, D., Yoshiji, H., Andoh, N., Horiguchi, K., Endoh, T., Kobayashi, E., Tsujiuchi, T., Shimoji, N., and Denda, M. (1994): Inhibitory effects of 2-O-octadecylascorbic acid and other vitamin $\mathrm{C}$ and $\mathrm{E}$ derivatives on the induction of enzyme-altered putative preneoplastic lesions in the livers of rats fed a choline-deficient L-amino aciddeficient diet. Carcinogenesis, 15, 241-246.

10. Munoz, E., Blagguez, M.V., Ortiz, C., Gomez-diez, C., and Navas, P. (1980): Role of ascorbate in the activation of NF-Kappa B by tumor necrosis factor-alpha in T-cells. Biochem. J., 40, 2796-2801.

11. Hoidal, J.R., Fox, R.B., and Le Marbe, P.H. (1981): Altered oxidative metabolic responses in vitro of alveolar macrophages from asymptomatic cigarette smokers. Am. Rev. Respir. Dis., 123, 85-89.

12. Church, D.F., and Pryor, W.A. (1985): Free-radical chemistry of cigarette smoke and its toxicological implications. Environ. Health Perspect., 64, 111-126.

13. Moldeus, P., Hogberg, J., and Orrenius, S. (1978): Isolation and use of liver cells. Methods Enzymol., 52, 60-71.

14. Ohkawa, H., Ohishi, N., and Yagi, K. (1979): Assay for lipid peroxides in animal tissues by thiobarbituric acid reaction. Anal. Biochem., 95, 351-358.

15. Ellman, G.L. (1959): Tissue sulfhydryl groups. Arch. Biochem. Biophys., 82, 70-72.

16. Misra, S., and Fridovich, I. (1972): The role of superoxide anion in the autooxidation of epinephrine and a simple assay for superoxide dismutase. J. Biol. Chem., 247, 3170-3175.

17. Takahara, S., Hamilton, B.H., Nell, J.V., Kobra, T.Y., Ogura, Y., and Nishimura, E.T. (1960): Hypocatalasemia: A new genetic carrier state. J. Clin. Invest., 29, 610-619.

18. Bacquer, N.J., and McClean, P. (1972): Evidences for the existence and functional activity of pentose phosphate pathway enzymes in the large particle fraction isolate from rat tissues. Biochem. Biophys. Res. Commun., 46, 167-174.

19. Paglia, D.E., and Valentine, W.N. (1967): Studies on the glutathione and glutathione characterization of erythrocyte glutathione peroxidase. J. Lab. Clin. Med., 82, 70-77.

20. Habig, W.H., Pabst, M.J., and Jakoby, W.B. (1974): Glutathione- $S$-transferases: The first enzymatic step in mercapturic acid formation. J. Biol. Chem., 249, 71130-71139.

21. Dubler, R.E., and Anderson, B.N. (1981): Simultaneous inactivation of the catalytic activities of yeast glutathione reductase by $N$-alkylmaleimides. Biochim. Biophys. Acta, 659, $70-$ 85.

22. Swinyard, E.A., and Pathak, M.A. (1980): Locally acting drugs and surface acting drugs, in Goodman and Gilman's Pharmacological Bases of the Therapeutics, ed. by Gilman, A.G.,

Vol. 26, No. 1, 1999 
and Goodman, L.S., 6th ed., Mac Millan Publishing Co., Inc., New York

23. Cohrane, C.G. (1991): Cellular injury by oxidants. Am. J. Med., 91(3C), 23-30.

24. Carmichael, J., Mitchell, J.B., Friedman, N., Gazdar, A.F., and Russo, A. (1988): Glutathione and related enzyme activity in human cell lines. Br. J. Cancer, 58, 437-440.

25. Younes, M., and Soegers, S. (1981): Mechanistic aspects of enhanced lipid peroxidation following glutathione depletion in vivo. Chem. Biol. Interact., 34, 257-266.

26. Schraufstatter, I.U., Hyslop, P.A., Jackson, J.H., and Cochrane, C.G. (1988): Oxidantinduced DNA damage of target cells. J. Clin. Invest., 4, 1040-1050.

27. De Flora, S., Benniceli, C., Zanacechi, P., Camoirano, A., Morelli, I., and De Flora, A. (1984): In vitro effects of $N$-acetyl cysteine on the mutagenicity of direct-acting compounds and procarcinogens. Carcinogenesis, 5, 505-510.

28. Russell, J., Spickett, C.M., Reglinski, J., Smith, W.E., Mc Murray, J., and Abdullah, I.B. (1994): Alteration of the erythrocyte glutathione redox balance by $N$-acetylcysteine, capotropil and exogenous glutathione. FEBS Lett., 347, 215-230.

29. De Flora, S., Bennicelli, C., Camoirano, A., Serra, D., Romano, M., Rossi, G.A., Morelli, A., and De Flora, A. (1985): In vivo effects of $N$-acetylcysteine on glutathione metabolism and on the biotransformation of carcinogenic and/or mutagenic compounds. Carcinogenesis, 6, 1735-1745.

30. De Flora, S., Romano, M., and Basso, C. (1986): Detoxifying activities in alveolar macrophages of rats treated with acetyl cysteine, diethyl maleate and/or aroclor. Anticancer Res., 6, 1009-1012.

31. De Flora, S., Astengo, M., Serra, D., and Bennicelli, C. (1986): Inhibition of urethaneinduced lung tumors in mice by dietary $N$-acetylcysteine. Cancer Lett., 32, 235-241.

32. Lutz, W., and Stankiewicz, A. (1995): Glutathione- $S$-transferase as a metabolic biomarker for predisposition to lung neoplasms induced by chemical carcinogens. Med. Proc., 46, 497503.

33. Beyer, R.E. (1994): The role of ascorbate in antioxidant protection of biomembranes: Interaction with vitamin $\mathrm{E}$ and coenzyme Q. J. Bioenerg. Biomembr., 26, 349-358.

34. Dalteon, D.A., Russell, H., Hanus, F.J., Pascoe, G.A., and Evans, H.J. (1986): Enzymatic reaction of ascorbate and glutathione that prevents peroxide damage in soybean root nodules. Proc. Natl. Acad. Sci. U.S.A., 83, 3811-3815.

35. Perchellet, J.P., Owen, M.D., Posey, T.D., Orten, B.K., and Schneider, B.A. (1985): Inhibitory effects of glutathione level-raising agents and $\mathrm{D}-\alpha$-tocopherol on ornithine decarboxylase induction and mouse skin tumor promotion by 12- $O$-tetradecanoylphorbol-13-acetate. Carcinogenesis, 6, 567-573.

36. Rotstein, J.B., and Slaga, T.J. (1988): Anticarcinogenic mechanism as evaluated in the multistage mouse skin model. Mutat. Res., 202, 421-427.

37. Greenwald, R.A. (1990): Superoxide dismutase and therapeutic agents for human diseases: A critical review. Free Radical Biol. Med., 8, 201-215. 